\title{
The writer is in
}

$\mathrm{N}$

ot too long ago I was in Ottawa doing some work for the Canada Council for the Arts. At the end of the meeting, the program director asked the three of us in attendance - writers all - what could be done to promote writing in Canada. We talked of the need for more money for manuscript editing, and more opportunities for writers to partake in career development and mentoring programs. My two colleagues described their experiences working as writers-in-residence at various universities and public libraries.

Then it occurred to me: What Canada needs is a national system of writers in residence at its hospitals.

The idea is not without precedent. Many medical schools incorporate the arts into their curricula ${ }^{1}$ and the University of Alberta has a program that allows artists to volunteer on the wards. Several medical schools around the world - among them Harvard University, New York University, University of Massachusetts, University of Limerick - have formal programs to support artists in residence. Memorial University of Newfoundland and Labrador had one in the past, but Dalhousie University in Halifax, Nova Scotia is, as far as I know, currently the only medical school in Canada with a formal artistin-residence program. It once hosted a poet: Glen Downie took up the post in 1999 with his book Wishbone Dance: New and Selected Medical Poems (Wolsak and Wynn, 1999), which drew on his years working in cancer care as a social worker. The Ontario Arts Council has also started a pilot project to support artists-in-residence in health care in that province.

A number of us in Canadian health care are creative writers already. Recall emergency physician Vincent Lam winning the Giller Prize in 2006 for Bloodletting \& Miraculous Cures (Doubleday, 2006). There is also neurologist Liam Durcan (e.g., A Short Journey by Car; Vehicule, 2005) and internist Kevin Pat-

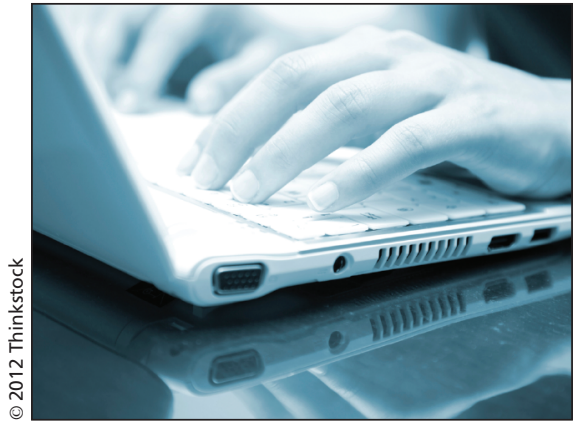

terson (e.g., Consumption; Vintage, 2007). Three physicians in my own clinic including yours truly have published books. Some of us write about medicine and some of us don't; not all writers want to be associated with a particular genre. Not that I think a hospital writer in residence should be a doctor; on the contrary, someone coming from a nonmedical perspective may stand to make more profound observations about medicine as it's practised today. My point about doctors who are writers is simply to underscore that medicine is fundamentally a narrative pursuit.

There are national bodies of academic physicians committed to promoting arts and humanities in medical education (the Canadian Association for Medical Education's "Arts, Humanities and Social Sciences in Medicine" Educational Interest Group is one), but they are not arts organizations per se. Columbia University has a graduate program in narrative medicine, founded and directed by internist and $\mathrm{PhD}$ in English literature Rita Charon; however, they are strict adherents to face-to-face teaching, so the only way to avail of that program is to take a year off work and move to New York City. Nice idea, but hard to swing for mere mortals.

None of these things gets at what a national program of writers-inresidence for hospitals could offer. A writer-in-residence might act partly as poet laureate who could comment (in the slant way that artists do) on life within the hospital walls, but also as a writing mentor for staff and patients who want help telling their own stories. (Some hospitals provide employees with gyms; think of this as - forgive me - a cultural boot camp.) He or she could give a public reading once in awhile, and bring a little culture to patients searching for comfort and meaning in their own illness experience. Hospitals have chapels for the same reason.

How would a writer-in-residence work? Maybe he or she would attend morning rounds. Perhaps visit with patients and scrub into surgery. Maybe spend a Friday night in the emergency department. Or befriend a few medical students and watch how they change over a year. I can hear cries of protest about confidentiality, but hospitals face (and surmount) the same issues with nonmedical personnel such as volunteers and chaplains all the time. In an era of increasing patient expectations, the mirror a writer could hold up to those of us responsible for providing care would be invaluable.

We wrapped up the meeting and went our separate ways, me with a little skip in my step about the possibilities. Later that night I met up with a poet friend of mine, and, over a pint or two, we talked about the joys, the slights, the opportunities, the lack of opportunities, that make up the writing life in Canada. It felt like home to be talking writing with a writer. I usually leave my inner writer at home when I go to work; I think part of me needs to keep my reflective life safe from the harsh fluorescent reality of the hospital. But as I walked home that night through the Ottawa snow, I thought maybe that's exactly the kind of change that health care needs.

\section{Monica Kidd MD \\ Resident \\ St. John's, NL}

\section{Reference}

1. Kidd MG, Connor JT. Striving to do good things: teaching humanities in Canadian medical schools. J Med Humanities 2008 29:45-54.

CMAJ 2012. DOI:10.1503/cmaj.120185 